\title{
SeedGermAnalysis Software Educativo Selecionador de Sementes Geradoras de Plantas
}

\author{
Larissa Thabáta Ferreira dos Santos ${ }^{1}$, Naiara Silva dos Santos ${ }^{2}$, Cláudio Lúcio \\ Fernandes Amaral ${ }^{3}$ \\ ${ }^{1}$ Centro de Pesquisa e Desenvolvimento de Software - Universidade Estadual do \\ Sudoeste da Bahia (UESB) \\ Rua José Moreira Sobrinho - Jequié - BA - Brazil \\ ${ }^{2}$ Departamento de Ciências e Tecnologias - UESB \\ ${ }^{3}$ Departamento de Ciências Biológicas UESB
}

larissa_thabata@hotmail.com,\{naiara.uesb,materdidatic\}@gmail.com

\begin{abstract}
The present paper has the purpose to facilitate the development of research and learning in the studies of Genetic Improvement of Plants and Analysis of Seed Germination, through educational software, accessible, called SeedGermAnalysis. It was developed in a web platform, based on the agile method of development Extreme Programming (XP) and, after its conclusion, had its usability demonstrated through a questionnaire answered by students of the area of genetics.
\end{abstract}

Resumo. O presente trabalho objetiva facilitar o desenvolvimento das pesquisas e do aprendizado nos estudos de Melhoramento Genético de Plantas $e$ Análise de Germinação de Sementes, através de um software educativo desenvolvido, acessível, denominado SeedGermAnalysis. Foi desenvolvido em plataforma web, baseado no método ágil de desenvolvimento Extreme Programming (XP) e, após a sua conclusão, teve sua usabilidade demonstrada através de um questionário respondido por estudantes da área de genética.

\section{Introdução}

A função de um software educativo é a de promover a aprendizagem de conhecimentos específicos com o seu uso, através de uma interface que esteja de acordo com princípios pedagógicos adequados, atendendo os requisitos de maneira adequada. Entretanto, atualmente existe uma distância entre as expectativas geradas e a realidade dos softwares disponíveis [Gomes e Wanderley 2003]. Além disso, vale ressaltar a importância de automatizar cálculos e processos, que são passíveis ao erro humano, uma vez que o estudo do melhoramento genético requer a análise de muitos dados, e cálculos estatísticos sobre os mesmos. O melhoramento genético de plantas tenta, cada vez mais, solucionar os variados problemas relacionados à relação de produtividade, estabilidade da produção vegetal e qualidade do produto agrícola, hortícola e silvícola [Amaral 2013]. 
Portanto, este trabalho mostra-se relevante e objetiva facilitar o desenvolvimento das pesquisas e do aprendizado nos estudos de Melhoramento Genético de Plantas e Análise de Germinação de Sementes, e automatizar as etapas realizadas nesses estudos, utilizando o SeedGermAnalysis, considerando no mesmo implicações pedagógicas, critérios de usabilidade, e uma perspectiva interativa.

\section{Revisão da Literatura}

Esta seção apresentará conceitos relacionados aos softwares educativos, bem como os conceitos de melhoramento genético de plantas e as causas que levaram à valorização deste tema no campo da genética e quais os softwares existentes na área.

\subsection{Softwares Educativos}

O conceito de software educativo está relacionado, segundo Gomes e Wanderley (2003), ao conjunto de artefatos criados para funcionarem enquanto mediadores em atividades educativas de formação em áreas distintas do conhecimento, tendo como função a promoção da aprendizagem para o uso, mas também da aprendizagem de conceitos específicos que ocorrem com a utilização do software. Em outras palavras, de acordo com os autores, as interfaces educativas contemplam seus requisitos quando os usuários aprendem a usá-las, e ao fazer isto, aprendem algo ou algum conceito novo.

\subsection{Melhoramento Genético de Plantas}

O melhoramento de plantas pode ser definido como "a arte e a ciência que visam à modificação gênica das plantas para torná-las mais úteis ao homem", que está fundamentado no conhecimento das áreas de genética, fisiologia, estatística, botânica, bioquímica e agronomia, o que a torna mais ciência do que propriamente arte [Borém e Miranda 2007].

A composição genética atual das diversas culturas é resultado da domesticação e melhoramento a que elas foram submetidas com o passar dos séculos, permitindo que melhoristas criem novos tipos de plantas, pela modificação dirigida dos caracteres hereditários [Borém e Milach 1999].

\subsection{Importância do Melhoramento Genético de Plantas}

Com o crescimento populacional, é importante discutir-se sobre o aumento da produção de alimentos, que só pode ser feita de três maneiras, segundo Borém (2005): através da expansão da área cultivada, melhoria das condições do ambiente, e, por fim, através do melhoramento genético, forma mais viável.

Neste cenário, é constante a busca de soluções para os diversos problemas agronômicos relacionados à redução de produtividade, o que alerta os geneticistas e fitotecnistas para a questão de melhoramento genético de plantas, através do manejo das práticas culturais, ambos, visando direta ou indiretamente, o aumento da produtividade agropecuária, estabilidade da produção vegetal e qualidade do produto agrícola, hortícola e silvícola, de acordo com Amaral (2013). 
VI Congresso Brasileiro de Informática na Educação (CBIE 2017)

Anais dos Workshops do VI Congresso Brasileiro de Informática na Educação (WCBIE 2017)

\subsection{Seleção de Sementes Geradoras de Plantas}

Um dos maiores desafios do melhorista é, segundo Borém e Miranda (2007), desenvolver variedades melhoradas. Ainda segundo os autores, a seleção de sementes somente é efetiva quando estão presentes diferenças hereditárias ou genéticas. Portanto, este processo somente é utilizado quando há populações que apresentam variabilidade genética, seja através da mistura de sementes de outras populações, por mutações genéticas, ou cruzamentos naturais com plantas de diferentes genótipos. Assim, a seleção de sementes pode ser feita através da Seleção de Linhas Puras, baseada no genótipo, e da Seleção Massal, método altamente influenciado pelo ambiente (fenótipo).

\subsection{Trabalhos Correlatos}

Existem diversos softwares correlatos, conforme mostra a tabela 1. O Software Genes é um programa gratuito, utilizado na análise biométrica; O Numeral Taxonomy and Multivariate Analysis System (NTSys) é um software de análise molecular; R é uma linguagem de programação, que aliada a um ambiente integrado permite a manipulação de dados, realização de cálculos e geração de gráficos; o Selegen-Reml/Blup possui metodologias de seleção genética a partir da análise matemática e estatística de dados obtidos em experimentos de campo; o Saeg é um software projetado para ser utilizado em análises estatísticas, que foi sofrendo melhorias ao longo do tempo; o Divergen é um programa estimador de diversidade genética em plantas, e diferencia-se do Selectress devido a este executar cálculos referentes aos índices dos fatores ambientais estressantes que influenciam na produção agrícola; o Hybridus é um sistema web aplicado ao melhoramento genético de plantas por meio de hibridação; e, por fim, o BioEstat é um programa de análises estatísticas, gratuito, voltado para quem possui noções básicas de estatística.

Portanto, em relação aos softwares apresentados, o SeedGermAnalysis se destaca devido a sua especificação, ou seja, por se tratar de uma ferramenta web para a seleção de sementes geradoras de plantas, com os cálculos específicos, descritos no capítulo 4, que ainda não foram implementados em nenhuma ferramenta. Além disso, possui o caráter de software educativo, com princípios pedagógicos adequados, multidisciplinar, interface amigável, além da promoção do conhecimento e a acessibilidade.

Tabela 1: comparativo dos softwares correlatos

\begin{tabular}{|l|l|l|l|l|l|}
\hline \multicolumn{1}{|c|}{ Softwares } & $\begin{array}{l}\text { Software de Análise de } \\
\text { Germinação de Sementes }\end{array}$ & Acessivel & Software Educativo & Em Português & Plataforma Web \\
\hline Genes & Não & Não & Não & Sim (e Inglês) & Não \\
\hline NTSys & Não & Não & Não & Não & Não \\
\hline $\boldsymbol{R}$ & Não & Não & Não & Não & Não \\
\hline Selegen & Não & Não & Não & Sim & Não \\
\hline Saeg & Não & Não & Não & Sim & Não \\
\hline Divergen & Não & Não & Sim & Sim & Não \\
\hline Selectress & Não & Não & Sim & Sim & Sim \\
\hline Hybridus & Não & Não & Sim & Sim & Sim \\
\hline BioEstat & Não & Não & Não & Sim & Não \\
\hline SeedGermAnalysis & Sim & Sim & Sim & Sim & Sim \\
\hline
\end{tabular}

\section{Metodologia}

Conforme a taxonomia proposta por Vergara (2009), esta pesquisa, quanto aos fins, foi metodológica e aplicada, e de campo, bibliográfica e participante, quanto aos meios. 
A amostra foi não probabilística por acessibilidade e por tipicidade. Foi composta 19 (dezenove) estudantes, na área de Ciências Biológicas e da Terra, especializados e focados nos estudos de diversidade genética e melhoramento genético.

A metodologia de desenvolvimento utilizada foi a Extreme Programming (XP), engenharia de software ágil. Segundo Presner e Santos Júnior (2014), XP "é uma metodologia ágil para equipes pequenas e médias e que irão desenvolver software com requisitos vagos e em constante mudança".

\section{O SeedGermAnalysis}

A página inicial do SeedGermAnalysis (Figura 1) contém três módulos: o módulo teórico, que possui capítulos com assuntos pertinentes à análise de germinação de sementes; O módulo prático, o qual calcula os índices relacionados à análise de germinação de sementes, que são Taxa de Germinação, Frequência Relativa de Germinação, Tempo de Germinação, Velocidade de Germinação, Coeficiente de Uniformidade de Germinação, Índice de Sincronização, Energia para Germinação, Taxa de Emergência de Plântulas, Velocidade de Emergência, Índice de Vigor das Plântulas, Índice de Qualidade das Mudas, e Umidade das Sementes; e, por fim, o módulo de ajuda, ), onde contém todas as informações relacionadas ao módulo teórico, além de guiar o usuário no correto preenchimento de todas os passos do módulo prático.

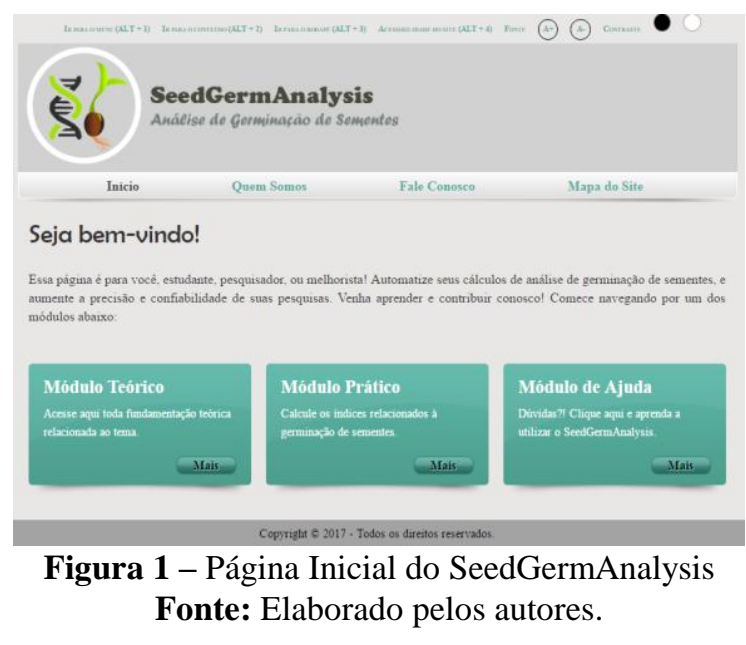

\section{Resultados}

A fim de comprovar o sucesso no alcance dos objetivos propostos, foi feita uma análise de usabilidade do sistema construído, e os resultados estão ilustrados no gráfico 1. Alguns critérios foram analisados, solicitando aos entrevistados que classificassem cada item de 1 a 5, em Muito Ruim, Ruim, Razoável, Bom ou Ótimo. Os itens analisados foram: 1 - Organização das Informações; 2 - Facilidade de Uso; 3 - Atratividade das Telas; 4 - Capacidade do sistema transmitir o assunto; 5 - Mensagens do sistema para o usuário; 6 - Nomenclatura utilizada nas telas (títulos, campos, etc); 7 - Desempenho do sistema; 8 - Clareza nas informações encontradas no Módulo Teórico; e 9 - Organização da informação na tela.

Ao fim da análise, foi calculada uma média aritmética com todas as notas atribuídas a cada item, e, conforme o gráfico a seguir, os seguintes resultados foram obtidos: 
VI Congresso Brasileiro de Informática na Educação (CBIE 2017)

Anais dos Workshops do VI Congresso Brasileiro de Informática na Educação (WCBIE 2017)

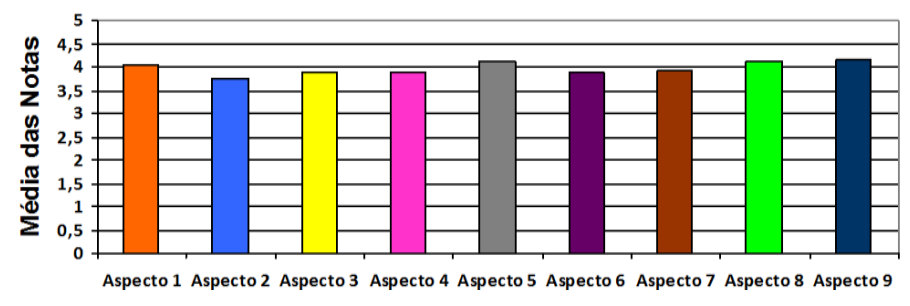

Gráfico 1 - Análise de Usabilidade do SeedGermAnalysis Fonte: Elaborada pelos autores.

\section{Conclusões}

Amparado pelos testes de usabilidade e os resultados desta pesquisa, pode-se concluir que o software desenvolvido, o SeedGermAnalysis, facilita o desenvolvimento das pesquisas, bem como do ensino e aprendizado de Análise de Germinação de Sementes, portanto poderá ser de grande utilidade nesta área do conhecimento, e que foi implementado segundo as necessidades reais dos usuários, com foco na usabilidade, um dos pilares de grande relevância no desenvolvimento de softwares educativos. Entretanto, faz-se necessário analisar os aspectos negativos que envolveram a produção desta ferramenta, os quais ficaram evidenciados na análise de usabilidade, e obtiveram notas mais baixas, e corrigir tais aspectos, a fim de aumentar a relevância do programa e sua usabilidade.

\section{Referências}

Amaral, C. L. F. (2013) "Estratégias da Seleção de Sementes Geradoras de Plantas: Matrizes Sadias Produtoras de Mudas Superiores em Programas de Melhoramento Vegetal”. Vitória da Conquista, Bahia.

Borem, A. (2005) "A História da Biotecnologia". In: Biotecnologia Ciência \& Desenvolvimento n. 34, p. 10-12.

Borem, A. e Miranda, G. V. (2007) "Melhoramento de Plantas". Viçosa: Editora UFV, $4^{\mathrm{a}}$ edição. 525p.

Borem, A. e Milach, S. C. K (1999) "Melhoramento de Plantas: o Melhoramento de Plantas na Virada do Milênio. Revista Biotecnologia Ciência \& Desenvolvimento". Encarte especial, Ano 2, n. 7, p. 68-72.

Gomes, A. S.e Wanderley, E. G. (2003) "Elicitando Requisitos em Projetos de Softwares Educativos". IX Workshop de Informática na Escola - WIE”, p. 119-130.

Presner, D. H., Santos Junior, E. L. (2014) "Estudo sobre metodologias ágeis de desenvolvimento aplicando a metodologia extreme programming em uma aplicação web". 60 f. Trabalho de Conclusão de Curso (Graduação) - Universidade Tecnológica Federal do Paraná, Ponta Grossa, 2014.

Vergara, S. C. (2009) "Projetos e Relatórios de Pesquisa em Administração". 11. Ed. São Paulo: Atlas. 